\section{Caminhos para a construçãe de uma política de comunicação para a qualidade: - papel das Relações Públicas}

\section{RESUMO}

O presente artigo apresenta uma breve discussão sobre a implantação do programa de qualidade total, bem como uma reflexão sobre as possibilidades de construção de uma política ou políticas de comunicação de qualidade e para a qualidade na universidade.

\section{ABSTRACT}

This study presents a brief analysis of total quality programs, their norms and their ideas, as well as their communication policies regarding their goals. Quality has recently become a major challenge to high level educational institutions in Brazil, for it is now usual to submit students and establishments to a national test of quality.

\section{PALAVRAS-CHAVE/KEY-WORDS}

- Comunicação (Communication)

- Universidade (University)

- Qualidade (Quality)

\section{Cleusa Maria A. de Scroferneker}

Profa. Dra.do PPGCOM da FAMECOS/PUCRS

\section{Introduçã̄o}

VIVE-SE A ERA DA INFORMAÇÃO, dos avanços e inovações tecnológicas, que invadem e transformam o ambiente organizacional. As organizações precisam redefinir-se, readaptar-se, enfim reorganizar-se para as mudanças. Inúmeras têm sido as alternativas sugeridas e adotadas pelas organizações para adequar-se a esse novo cenário: Downsizing, Empowering, Qualidade Total. No caso específico da qualidade total os aspectos que envolvem a sua implantação são geralmente associados à inovação. Drucker (1995, p. 3) considera o Gerenciamento da Qualidade Total " .. uma ferramenta de como fazer, ou seja, ... fazer de forma diferente aquilo que já é feito."

A Gerência de Qualidade Total - TQC (Total Quality Control) foi estruturada e aperfeiçoada no Japão pela JUSE (Union of Japanese Scientists and Engineers), e apresenta elementos do taylorismo; do controle estatístico do processo de Shewhart; conceitos de Maslow sobre o comportamento humano, aliado a todo o conhecimento ocidental de qualidade, principalmente os trabalhos de Deming e Juran.

É considerada um modelo de gestão que implica mudanças culturais significativas, exigindo, por sua vez, uma transformação de mentalidades, tendo em vista que o cliente se constitui a razão de ser da organização.

No Brasil, o Gerenciamento da Quali- 
dade Total vem sendo opção para um número significativo de organizações, inclusive na área da Educação . ${ }^{1}$ No âmbito da universidade a qualidade tem sido também uma preocupação fundamental e constante, principalmente no momento atual, em que inúmeras ações como o Exame Nacional de Cursos, conhecido como o Provão, o Programa de Avaliação Institucional das Universidades Brasileiras - PAIUB e os Padrões de Qualidade utilizados pelas Comissões de Especialistas da Secretaria de Ensino Superior do Ministério de Educação SESu/MEC vêm sendo desenvolvidas. Talvez seja essa preocupação que tem levado algumas instituições de Ensino Superior a recorrer a um programa de qualidade total. Essa observação permite indagar: será viável a implantação de um programa de qualidade total, considerando as especificidades da área educacional e especialmente do ensino superior?

As especificidades dessa organização exigem uma profunda reflexão sobre o que representará a sua implantação. Se realmente é adotada a partir da constatação da necessidade de mudança, se não se trata de um modismo que assume; e se as organizações educacionais (escolas, universidades) estarão efetivamente interessadas em rever, reavaliar e repensar sua missão, sua estrutura interna (valores, corporativismos...) e seu papel na e para a sociedade.

A implantação do programa de qualidade se constitui, essencialmente, em um processo de educação e treinamento, que precisa ser assumido integralmente pela alta administração. É um programa voltado para mudanças de um sistema de métodos gerenciais que exige da organização uma revisão de seus valores fundamentais, seus princípios, sua visão de futuro e sua estratégia de ação a médio e a longo prazo.

Pressupõe a participação de todos, independentemente dos cargos e funções na hierarquia organizacional.

As ações voltam-se para a satisfação das necessidades das pessoas - dos clientes.

A adoção do termo cliente para a insti- tuição de ensino tem recebido inúmeras críticas pela tentativa de transformar a educação em uma área de prestação de serviços (Chauí, 1999). A questão principal não está propriamente no termo, mas no tipo de relações que a sua adoção pressupõe. Pode-se escolher ser cliente de um banco, de uma loja, de uma companhia aérea. Mas o que significa ser cliente, por exemplo como aluno, de uma universidade? O que significa ter as necessidades atendidas?

Cristovam Buarque (1994) afirma que houve uma perda de qualidade na Universidade, no sentido de que ela deixou de ser vanguarda de sua qualidade funcional. Porém, não é possível imaginar a universidade sem qualidade. Por isso complementa que a universidade deve ter tanta qualidade que defina o seu próprio conceito de qualidade.

É provável que a implantação do programa de qualidade total possa contribuir para a construção de seu conceito de qualidade. Mas considerando que a decisão pela qualidade total se dá de cima para baixo, que a alta administração deve assumir o compromisso pela sua implantação, contar com o apoio de lideranças atuantes e com o engajamento de todos, a tendência é que a implantação do programa seja dificultada, até pela ausência de uma discussão mais ampla da sua necessidade e pertinência.

Aliam-se a esses fatores: a dimensão da universidade enquanto estrutura administrativo-organizacional, sua fragmentação em unidades e departamentos, a seleção de áreas internas de excelência, as disputas de poder entre as diferentes áreas (vinculadas a titulações, produção científica, hierarquias funcionais...) antigüidade, seu corporativismo, além da sua tendência natural de reagir a mudanças.

Somam-se às dificuldades mencionadas e que se constituem em obstáculos à implantação da gestão da qualidade total, a ineficiência da comunicação na universidade. A ausência de políticas de comunicação claramente definidas compromete toda e qualquer proposta de mudança. Geralmen- 
te os segmentos envolvidos: professores, alunos, funcionários, não são "comunicados" , nem convidados a refletir sobre o significado dessas mudanças e do impacto no seu cotidiano.

Algumas questões permanecem em aberto: como viabilizar a implantação de um modelo gerencial mais humano, mais participativo e mais motivador, fundamentado no diálogo, desconsiderando a relevância da comunicação? Da construção de uma política de comunicação para a qualidade que possibilite a participação e interação dos públicos internos envolvidos?

O presente artigo apresenta uma reflexão sobre as possibilidades de construção de uma política ou políticas de comunicação para a qualidade na universidade.

Que procedimentos adotar? Que passos ou etapas seguir? Não há intenção de propor fórmulas ou modelos para a construção dessa política, pois considera-se que as particularidades de cada universidade devam ser priorizadas quando da sua construção.

\section{A construção de uma política de comu- nicação para a qualidade}

É importante esclarecer que, por política de comunicação, entende-se um elenco de ações e estratégias planejadas e integradas direcionadas aos públicos da universidade, priorizando os seus públicos internos. $\mathrm{Na}$ universidade, portanto, essa política precisa voltar-se inicialmente para alunos, funcionários e professores.

Mas diferentemente da implantação de um programa de qualidade, uma política de comunicação para a qualidade não se impõe, necessita ser construída. Demanda um profundo conhecimento dos públicos à qual se destina e com os quais interage, o conhecimento de suas expectativas e frustrações. Não se trata de pesquisa de opinião, mas de ouvir e querer escutar, de olhar e querer ver, de falar e deixar falar e principalmente, promover ações que trans- pareçam o reconhecimento e o respeito pela participação e interação efetivas, e não somente 'festivas'. Isso significa dizer que a construção desta política se inicia com a auditoria de comunicação na universidade, a partir de duas dimensões: a da comunicação administrativa e da comunicação interna. A comunicação administrativa refere-se a todos os procedimentos comunicacionais que ocorrem na organização por meio dos seus fluxos descendente, ascendente e lateral, das redes formais e informais e dos veículos (canais escritos, orais,...) utilizados.

De acordo com Kunsch (1995, p. 92) "esse tipo de comunicação é fundamental para o processamento das informações no âmbito das funções administrativas". A comunicação interna, por sua vez, se desenvolve paralelamente à comunicação administrativa, a qual, inclusive, lhe dá suporte.

É viabilizada (ou deveria ser) mediante inúmeras ações e estratégias comunicacionais planejadas, visando fundamentalmente a interação entre os públicos, o diálogo e a participação. A falta de comunicação e informação tende a gerar situações conflitantes e desagradáveis.

A primeira ação concreta dessa política de comunicação para a qualidade é o conhecimento de como está a comunicação na universidade, por meio de um levantamento criterioso dos procedimentos comunicacionais administrativos adotados e os canais que tem sido utilizados.

Como as informações estão chegando aos funcionários? Tem havido preocupação com a adequação da linguagem buscando respeitar e considerar as especificidades dos funcionários que compõem a universidade, possibilitando que a comunicação ocorra? As mensagens estão sendo compreendidas pelo guarda da guarita, pela cozinheira do restaurante universitário, pela secretária do reitor? Os funcionários tem recebido as informações para que possam responder adequadamente e com precisão às solicitações dos alunos, dos professores e da comunidade em geral?

Professores e alunos têm conseguido 
esclarecer as suas dúvidas e manifestar as suas ansiedades e expectativas? Como a comunicação se realiza entre professores e alunos, administração e professores, administração e alunos, professores e secretarias, alunos e secretarias, professores e professores?

É comum deparar-se com situações em que professores que atuam na mesma faculdade não se conhecem, e somente se 'reconhecem' pelo uso de alguma identificação que por ventura a universidade tenha adotado como norma, como por exemplo, um crachá. Que dirá no campus universitário, onde centenas de professores, alunos e funcionários circulam diariamente?

Como a universidade tem buscado aproximar os seus públicos? Essa é uma segunda dimensão a ser considerada, isto é, a comunicação interna na universidade.

É comum eventos ocorrerem na universidade e tomar-se conhecimento depois que ocorreram. Normalmente as colocações são do tipo: foi divulgado no jornal, estava na home page, foi colocado no mural. Mas serão esses os melhores veículos à comunicação?

Como esses veículos estão sendo avaliados? Os públicos foram ouvidos? É sempre bom lembrar que jornal, mural, boletins, por exemplo, são instrumentos de comunicação impessoais.

Não raras vezes, ao entrar-se na sala dos professores, depara-se com o acúmulo de boletins e jornais da universidade sobre a mesa ou mesmo no lixo.

Acredita-se que a construção de uma política de comunicação para a qualidade e com qualidade poderia começar por considerar essas duas dimensões, tendo presente que a universidade é constituída por espaços policulturais, que necessitam ser compreendidos e interpretados, com vistas a uma avaliação da qualidade da sua comunicação. Porém, não significa somente verificar se a comunicação ocorre ou não, se é boa ou ruim. É preciso querer ler e interpretar as entrelinhas do que é dito, escrito e expressado. O professor Wilson
Costa Bueno afirmava em sua palestra no I Encontro de Comunicação Integrada da Universidade realizada na Universidade de São Paulo, em outubro de 1998, que a "universidade tem uma grande boca, e as orelhas pequenas" e caberia acrescentar que está a necessitar de óculos.

Portanto, a realização de auditoria da comunicação na universidade é fundamental. As auditorias de comunicação organizacional podem ser concebidas e realizadas a partir de perspectivas conceituais distintas (Varona, 1994):

a) Perspectiva funcionalista: concebe a organização como 'máquina' ou 'objetos' que podem ser estudados com os conceitos e métodos tradicionais das ciências sociais. Para essa perspectiva, o objetivo fundamental de uma auditoria é detectar e corrigir as práticas comunicacionais que estão impedindo a produção e a eficiência da organização.

b) Perspectiva funcionalista contemporânea: adota uma visão mais dinâmica do organização e do papel da comunicação organizacional. A organização é vista como um sistema vivo integrado por subsistemas e em constante interação com o sistema externo. Os seus métodos de análise e de interpretação incluem a análise de conteúdo e estatística. Utiliza como técnicas: entrevistas individuais e coletivas, o questionário (técnicas fundamentais em qualquer auditoria da comunicação), análise das redes de comunicação, análise da difusão das mensagens.

c) Perspectiva interpretativa: percebe as organizações como 'culturas', que possuem um conjunto de crenças e valores, e uma linguagem que se reflete nos símbolos, nos ritos, nas metáforas, no sistema de relações e no conteúdo das conversações. A atenção volta-se para o significado das ações e das produções comunicacionais, buscando apreender como os membros da organização percebem, experimentam e interpretam a vida organizacional sem impor nenhum conjunto de conceitos pré-estabe- 
lecidos. Utiliza-se da análise de conteúdo e tem na observação direta, entrevista e análise das produções comunicacionais seus principais instrumentos.

d) Perspectiva crítica: investiga como as práticas de comunicação organizacional são sistematicamente distorcidas para servir aos interesses dos detentores do poder na organização. Utiliza-se da coleta de informações e análise semelhantes aos utilizados pela perspectiva interpretativa.

Pela descrição e caracterização das diferentes perspectivas sugere-se realização de auditoria da comunicação sob a perspectiva interpretativa na universidade.

Contudo, a perspectiva funcionalista contemporânea de certa forma, acha-se igualmente adequada ao considerar-se a universidade metaforicamente como organismo. (Morgan, 1996). É importante que a própria universidade selecione a perspectiva que considerar pertinente e procure igualmente desenvolver e adequar métodos e técnicas para auditar a sua comunicação.

Chauí (1993, p.22) alerta que em uma universidade "(...) os objetos de trabalho são diferentes e regidos por lógicas, práticas e finalidades diferentes". E indaga

“Não seria um absurdo, por exemplo, se considerássemos que a linguagem simbólico-metafórica ou a polissemia que caracteriza a literatura e a filosofia fossem tratados da mesma maneira que a linguagem simbólica-algorítimica e unívoca da matemática ou da física?"

Essa mesma linha de raciocínio ajustase a aspectos relacionados à construção de uma política de comunicação para a qualidade, isto é, a aceitação e a compreensão da heterogeneidade da universidade.

Cabe lembrar que a construção desta política de comunicação para a qualidade deve ter como fundamentos a política de comunicação global da universidade, a qual não se resume na elaboração de jornais, e boletins coloridos e bem diagramados, ou espaços pagos na mídia. Portanto, a comunicação para a qualidade não deveria estar descolada da política de comunicação da própria universidade.

A política de comunicação da universidade necessita ser de conhecimento dos seus públicos, ser também compartilhada.

Daí acreditar-se que o planejamento da comunicação necessite apoiar-se numa perspectiva de comunicação integrada.

A proposição da comunicação integrada contudo precisará considerar a especifidade da universidade como instituição e como organização. Por isso, sugere-se que a sua adoção na universidade contemple a comunicação institucional, a comunicação interna e a comunicação administrativa, como descrito na figura abaixo:

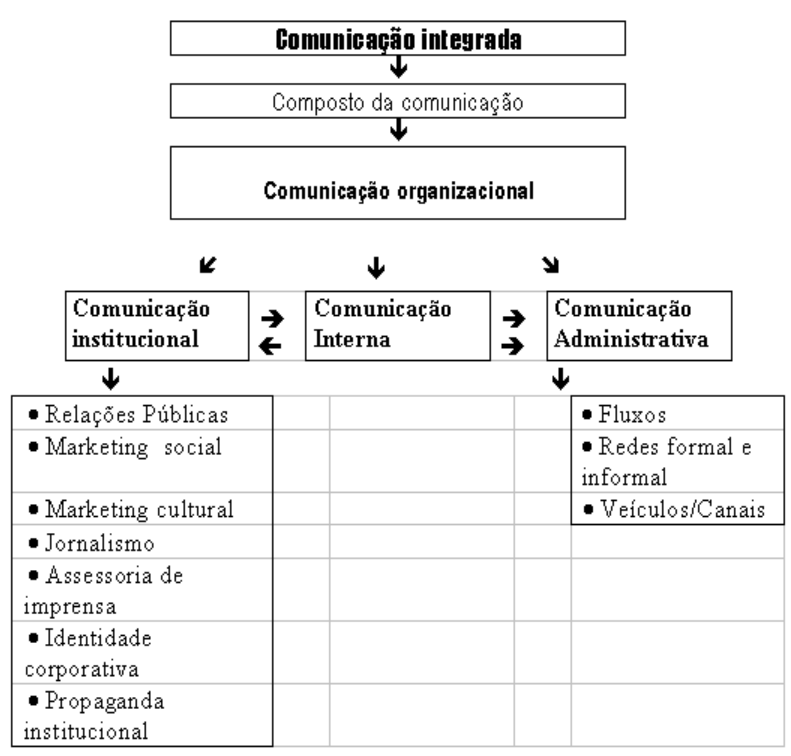

Fig. 1: Margarida Maria Krohling, Relações Públicas e Modernidade: Novos paradigmas na comunicação organizacional. Ed. Sumus Editorial. p.166 .

A exclusão da comunicação mercadológica do composto da comunicação para a universidade atendeu ao fato de acreditarse que a universidade não deveria ser tratada como um negócio empresarial. Admitese, contudo, que há alguns exemplos de universidades e faculdades que têm se utilizado de algumas das práticas dessa co- 
municação. As suas assessorias de comunicação são identificadas como de Comunicação e Marketing, voltando-se prioritariamente para uma visão mercadológica da universidade. Resta saber como a universidade quer ser reconhecida: pelas suas belas e bem produzidas campanhas, seu material promocional colorido, pelos seus patrocínios? $\mathrm{Ou}$, principalmente, pela qualidade do seu ensino, das suas pesquisas, do seu em envolvimento efetivo com a comunidade?

As três dimensões que compõem a comunicação organizacional na universidade foram colocadas propositalmente no mesmo plano, significando que são complementares e bi-direcionais.

Propõe-se, assim, que, a partir da definição da política global de comunicação da universidade, o seu planejamento considere as dimensões apresentadas.

A elaboração deste planejamento poderá ater-se a uma série de etapas já desenvolvidas por Kunsch $\left(1986^{2}, 1992^{3}, 1997^{4}\right)$ e que compreendem: pesquisa e auditoria, elaboração de briefing, análise e construção de diagnóstico, definição da missão da comunicação, estabelecimento de filosofias e políticas, determinação de objetivos e metas, esboço de estratégias gerais, relacionamento dos programas específicos, montagem do orçamento geral, divulgação do plano, implementação, controle de ações e avaliação dos resultados.

A adoção de uma política de comunicação global na universidade e todo o planejamento dela decorrente são decisões políticas. Portanto, a consecução de um planejamento de comunicação integrada atendendo às etapas mencionadas pressupõe um comprometimento efetivo da alta administração da universidade e necessariamente deve ser compartilhado com todos os segmentos que a compõem. Professores, alunos e funcionários precisam conhecer esse planejamento, para que possam contribuir para a sua melhoria e aperfeiçoamento.

É importante também estabelecimento de espaços de oralidade, isto é, palestras, seminários, cursos, debates, onde esses públicos possam questionar, esclarecer suas dúvidas e principalmente sugerir, opinar, ouvir e possam sentir-se ouvidos, legitimando a sua participação.

Portanto, uma política global de comunicação que admita a participação dos seus públicos igualmente pressupõe a substituição do modelo de comunicação tradicional, de caráter informacional.

\section{- papel das Relações Públicas}

Ao tratar do papel das Relações Públicas na construção de uma política de comunicação para a qualidade a está considerando, de acordo com a visão de Grunig (1994) como a atividade responsável pela gestão da comunicação na organização. Tal posicionamento se faz necessário, pois como bem alertou Simões (1995) o termo Relações Públicas é polissêmico, admitindo uma pluralidade de significados: processo, função, atividade, profissional, cargo, profissão, os quais podem ser encontrados nas suas inúmeras definições ${ }^{5}$. Contudo, cabe ressaltar que o viés que permeia essa pluralidade está no seu objeto de estudo, isto é, na relação organização-públicos.

Assim, é da responsabilidade das Relações Públicas, a gestão da comunicação em toda a sua amplitude e complexidade, estabelecendo a mediação entre a organização e seus públicos. Mediação essa marcada pela fortalecimento do diálogo e da interação. É sob essa perspectiva que as Relações Públicas necessita ser desenvolvida e reconhecida na universidade.

As Relações Públicas como gestora dos processos comunicacionais pode auxiliar as organizações no seu processo de comunicação estratégica, fazendo com que primeiro se conheçam a si próprias, para posteriormente melhor se comunicarem com seus públicos externos. (Freitas, 1997).

E Kunsch acrescenta:

“ pela natureza de suas atividades e 
pelo seu objeto de estudo (público/ organização), as Relações Públicas devem, por obrigação, pensar e agir estrategicamente em busca de uma comunicação simétrica."

Grunig (1994) buscou sistematizar a prática das Relações Públicas nas organizações, considerando-a sob duas perspectivas: as Relações Públicas assimétricas e as Relações Públicas simétrica. Na assimetria há o desequilíbrio na relação organizaçãopúblicos e é identificada como Relações Públicas de 'mão única', pois visa exclusivamente à difusão da informação, enquanto na perspectiva simétrica há a busca do equilíbrio nessa relação, isto é, as Relações Públicas é uma via de "mão dupla", voltada para o diálogo, para a troca de informações. Essas duas perspectivas foram representadas através de quatro modelos. $\mathrm{O}$ termo modelo para Grunig significa uma representação simplificada da realidade e os termos assimétrico e simétrico, mão única e dupla mão para descrever respectivamente o propósito e a direção das Relações Públicas na busca da comunicação. Os quatro modelos foram sintetizados na Figura 2:

\begin{tabular}{|c|c|c|c|c|}
\hline $\begin{array}{l}\text { CARACTERÍS } \\
\text { TICAS }\end{array}$ & \begin{tabular}{|c|} 
DE \\
$\substack{\text { IMPRENSA/PRO- } \\
\text { PAGANDA }}$
\end{tabular} & $\begin{array}{c}\text { DE } \\
\text { INFORMACRAO } \\
\text { PÚBLICA }\end{array}$ & $\begin{array}{l}\text { ASSIMÉTRICO DE } \\
\text { MÄO DUPLA }\end{array}$ & $\begin{array}{l}\text { SIMÉTRICO DE } \\
\text { DUAS MÄOS }\end{array}$ \\
\hline Objetivo & 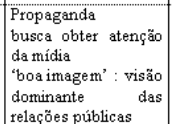 & \begin{tabular}{|l|} 
Disseminaçáo da \\
informaçäo \\
"boa imagem" \\
visão dominante das \\
relações públicas
\end{tabular} & $\begin{array}{ll}\text { Persuasáo } & \text { e } \\
\text { manipulação dos } \\
\text { públicos } \\
\text { 'boa imagem' } \\
\text { visão dominante das } \\
\text { relaçöes públicas }\end{array}$ & $\begin{array}{l}\text { Compreensão mútua } \\
\text { 'quebra da visão } \\
\text { dominante de relaçôes } \\
\text { públicas'. }\end{array}$ \\
\hline $\begin{array}{l}\text { Natureza da } \\
\text { comunicą̧ão }\end{array}$ & 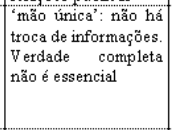 & $\begin{array}{l}\text { 'mão única': nåa hấ } \\
\text { troca de informaçōes. } \\
\text { Verdade } \\
\text { importante. }\end{array}$ & $\begin{array}{l}\text { 'dupla măo' } \\
\text { efeitos assimétricos: } \\
\text { a expectativa de } \\
\text { mudança beneficia a } \\
\text { organizą̧ăo e näo os } \\
\text { públicos. }\end{array}$ & $\begin{array}{l}\text { 'dupla măo' } \\
\text { efeitos simétricos: a } \\
\text { expetativa de mudanģa } \\
\text { beneficia a organizaçăo } \\
\text { e os públicos. }\end{array}$ \\
\hline $\begin{array}{l}\text { Processo de } \\
\text { comunicąăäo }\end{array}$ & Fonte $\rightarrow$ Receptor & Fonte $\rightarrow$ Receptor & $\underset{\text { fretaback }}{\text { Grupo }}$ & Grup $\vec{\leftarrow}$ \\
\hline Usos típicos & $\begin{array}{l}\begin{array}{l}\text { Promoģåa } \\
\text { produtos }\end{array} \\
\end{array}$ & $\begin{array}{|ll|}\text { Governo } & \\
\text { Associaçöes } & \text { não } \\
\text { lucrativas } & \\
\text { Organizacöes } & \\
\end{array}$ & $\begin{array}{l}\text { Empresas } \\
\text { competitivas } \\
\text { Agências }\end{array}$ & $\begin{array}{l}\text { Empresas } \\
\text { Agências }\end{array}$ \\
\hline
\end{tabular}

Fig. 2: Os modelos de relações públicas( Grunig \& Hunt, 1994).

Fonte: Elaborado a partir de Kunsch, Margarida M. K. Relações Públicas e Modernidade: Novos paradigmas na comunicação organizacional. São Paulo: Summus, 1997, p. 110. Moura, Cláudia Peixoto de e Scroferneker, Cleusa Maria Andrade . Relações públicas x função política e a administração de conflitos/controvérsias nas organizações. In: Comunicação, marketing, cultura: sentidos da administração, do trabalho e do consumo. São Paulo: ECA/ USP: CLC, 1999.

Esse autor defende as Relações Públicas simétrica de mão dupla como a desejável para as organizações, que se constitui no dizer de Kunsch (1997, p. 110) "na visão mais moderna de relações públicas, em que há busca de equilíbrio entre os interesses da organização e dos públicos envolvidos". Enfatiza os públicos prioritários em detrimento da mídia.

Grunig admite, no entanto, que os modelos de Relações Públicas assimétricas, de mão única, são mais usuais, especialmente as de imprensa/propaganda e de informação pública. O primeiro objetiva a publicação de notícias sobre a organização, buscando despertar o interesse da mídia. O segundo modelo objetiva a disseminação da informação por meio da mídia em geral e de meios específicos.

Simões (1995, p.88) considera que as Relações Públicas de mão dupla " é sempre viável e exequuível com os públicos internos", mas que oferece algumas dificuldades em relação "ao trânsito no sentido inverso" com os públicos externos.

Acredita-se que a política de comunicação global da universidade necessita valorizar e estimular a comunicação simétrica, rompendo com o paradigma assimétrico que vem norteando as suas comunicações, especialmente internas, apoiando-se, portanto, no modelo de Relações Públicas simétrica.

Com base nessas colocações, é possível reforçar que não há como construir uma política de comunicação para a qualidade e com qualidade fora do contexto mais amplo da comunicação da universidade. Aliás, não há como pensar em políticas específicas de comunicação desarticuladas.

Concorda-se com Restreppo (1995) quando afirma que a maneira de ser de uma organização pode ser interpretada pelas formas de comunicação que ali são desenvolvidas. Três questões merecem ser colocadas: quais as formas de comunicação 
que a universidade tem utilizado? Como as tem avaliado? O seu discurso está coerente com as suas práticas? É preciso refletir sobre isso, até porque percebe-se um distanciamento (ou, quem sabe, desconhecimento) da administração da universidade em relação à importância da comunicação, bem como das relações públicas como mediadora e gestora desta comunicação.

Implantar um programa de qualidade total na universidade é uma decisão que necessita ser amplamente discutida e avaliada pela própria universidade. Porém, independentemente da decisão tomada, há necessidade de construir-se uma política de comunicação, se não para a qualidade, mas fundamentalmente com qualidade.

É importante ainda mencionar que não houve preocupação em enfatizar no decorrer nesse artigo o papel da comunicação como ferramenta estratégica pelas mesma razões que se excluiu a comunicação mercadológica do composto da comunicação organizacional. Mas cabe destacar, que há uma tendência crescente de redimensionar o papel da comunicação nas organizações a partir desse pressuposto, considerando a “ (...) sua função estratégica de resultados, isto é, ela tem que agregar valores e ajudar as organizações a cumprirem a sua missão e concretizarem sua visão". ${ }^{6}$ É uma possibilidade que poderá ser considerada pela universidade, sem contudo desconsiderar a sua especificidade como organização e instituição.

Este é um convite à reflexão, lembrando que há alternativas de caminhos a serem percorridos... É uma questão de escolha ..•

\section{Notas}

Professora da Faculdade de Comunicação Social da Pontifícia Universidade Católica do Rio Grande do Sul FAMECOS/PUCRS e Doutora em Ciência da Comunicação pela Escola de Comunicação e Artes da Universidade de São Paulo - ECA/USP.

1 Minas Gerais foi o estado precursor na implantação de programa de Qualidade Total junto às Escolas estaduais, em 1992, com 0 apoio técnico-metodológico da então Fundação Christiano Ottoni. De lá para cá esta Fundação, atualmente conhecida como Fundação para o Desenvolvimento Gerencial (FDG) vem pretando consultoria a Instituições de Ensino, bem como produzindo um número significativo de obras voltadas para a implantação do Gerenciamento da Qualidade Total (TQC) na Educação.

2 Para o detalhamento dessas etapas, ver: Kunsch, Margarida M.K. Planejamento de relações públicas na comunicação integrada. 2a.ed. São Paulo : Summus, 1989.

\section{Universidade e comunicação na edificação da sociedade. São Paulo:} Loyola, 1992.

4 "Planejamento estratégico e excelência da comunicação". In: Obtendo resultados com relações públicas. São Paulo: Pioneira, 1997, pp.26-36.

5 Vide Moura, Claúdia Peixoto de e Scroferneker, Cleusa Maria Andrade. "Relações Públicas x função política e a administração de conflitos/controvérsias nas organizações". In: Comunicação, marketing, cultura: sentidos da administração, do trabalho e do consumo. São Paulo: ECA/USP: CLC. 1999, pp.203-227.

6 Palestra proferida no IV Fórum Ibero-Americano de Relações Públicas. Porto Alegre, RS, outubro de 1999.

\section{Referências}

BUARQUE, Cristovan. A aventura da universidade. São Paulo: Editora da Universidade Estadual Paulista. Rio de Janeiro: Paz e Terra, 1994.

CHANLAT, Alain e BÉDARD, Renée. "Palavras: a ferramenta do executivo". In: 0 indivíduo na organização: dimensões esquecidas. São Paulo: Atlas, 1993, v.1.

CHAUÍ, Marilena. "A universidade em ruínas". In: A universidade em ruinas na república dos professores. Petrópolis/RJ: Vozes, Porto Alegre/RS: CIPEDES, 1999.

."Universidade, ética e cidadania". $56^{\text {a }}$ Reunião Plenária do Conselho de Reitores das Universidades Brasileiras CRUB, Manaus (AM), 29 a 31 de março de 1993.

DRUCKER, Peter. Administrando em tempos de grandes mudanças. 
FREITAS, Sidinéia Gomes. "Cultura organizacional e comunicação". In: Obtendo resultados com relações públicas. São Paulo: Pioneira, 1997.

GRUNIG, James E. e HUNT, Todd. Managing Public Relations. Harcourt Brace Jovanovich College Publications, Orlando, Florida, USA, 1994.

KUNSCH, Margarida M.K. Planejamento de relações públicas na comunicação integrada. 2.ed. São Paulo: Summus, 1989.

Universidade e comunicação na edificação da sociedade. São

Paulo: Edições Loyola, 1992.

"Comunicação integrada nas organizações modernas: avanços e perspectivas no Brasil". In: Comunicação para o mercado, instituiç̧ẽes, mercado, publicidade. São Paulo: EDICON, 1995.

- Obtendo resultados com relações públicas. São Paulo: Pioneira, 1997 (Biblioteca Pioneira de administração e negócios).

- Relações públicas e modernidade: novos paradiogmas na Comunicação Organizacional. São Paulo: Summus, 1997.

LOUREIRO, Amilcar Bruno Soares, CAMPOS, Silvia Horst. Guia para elaboração e apresentação de trabalhos científicos. 2.ed. Porto Alegre: EDIPUCRS, 1999.

MADRID, Federico Varona. "Las auditorias de la comunicacion organizacional desde uma perspectiva estadounidense". Ensayo. (s.d), pp. 55-63.

MORGAN, Gareth. Imagens da organização. São Paulo: Atlas, 1996.

MOURA, Claudia Peixoto de, SCROFERNEKER, Cleusa Maria Andrade. "Relações públicas x função política e administração de conflitos/controvérsias nas organizações". In: Comunicação, marketing, cultura: sentidos da administração, do trabalho e do consumo. São Paulo: ECA/USP: CLC, 1999.

RESTREPPO, J. Mariluz. "Comunicación para la dinámica organizacional". Colombia: Signo y Pensamiento, n.26 (XIV) Universidad Javeriana: Facultad de Comunicación y Lenguage, 1995, pp. 91-96.

SIMÕES, Roberto Porto. Relações públicas: função politica. 3.ed. 